\title{
Discovery of Breast Cancers Within 1 Year of a Normal Screening Mammogram: How Are They Found?
}

\author{
Patricia A. Carney, $\mathrm{PhD}^{1,2}$ \\ Elizabeth Steiner, $M D^{2}$ \\ Martha E. Goodrich, MS ${ }^{1}$ \\ Allen J. Dietrich, $M D^{1}$ \\ Claudia J. Kasales, $M D^{3}$ \\ Julia E. Weiss, MS ${ }^{1}$ \\ Todd MacKenzie, $\mathrm{PbD}^{4}$ \\ 'Department of Community \& Family \\ Medicine, Dartmouth Medical School, \\ Lebanon, $\mathrm{NH}$ \\ ${ }^{2}$ Department of Family Medicine, Oregon \\ Health \& Science University School of \\ Medicine, Portland, Ore \\ ${ }^{3}$ Department of Radiology, Dartmouth \\ Medical School, Lebanon, $\mathrm{NH}$ \\ ${ }^{4}$ Department of Medicine, Dartmouth \\ Medical School, Lebanon, NH
}

Conflicts of interest: none reported

\section{CORRESPONDING AUTHOR}

Patricia A. Carney, PhD

Department of Family Medicine

Oregon Health and Science University

Sam Jackson Rd Mail Code: FM

Portland, OR 97239

carneyp@ohsu.edu

\begin{abstract}
PURPOSE We sought to determine how breast cancers that occur within 1 year after a normal mammogram are discovered.

METHODS Using population-based mammography registry data from 20002002, we identified 143 women with interval breast cancers and 481 women with screen-detected breast cancers. We surveyed women's primary care clinicians to assess how the interval breast cancers were found and factors associated with their discovery.
\end{abstract}

RESULTS Women with interval cancers were twice as likely to have a personal history of breast cancer (30.1\%) as women with screen-detected cancers (13.6\%). Among women with interval cancers, one half of the invasive tumors (49.5\%) were discovered when women initiated a health care visit because of a breast concern, and $16.8 \%$ were discovered when a clinician found an area of concern while conducting a routine clinical breast examination. Having a lump and both a personal and a family history of breast cancer was the most common reason why women initiated a health care visit $(44 \%)(P<.01)$.

CONCLUSIONS Women with interval cancers are most likely to initiate a visit to a primary care clinician when they have 2 or more breast concerns. These concerns are most likely to include having a lump and a personal and/or family history of breast cancer. Women at highest risk for breast cancer may need closer surveillance by their primary care clinicians and may benefit from a strong educational message to come for a visit as soon as they find a lump.

Ann Fam Med 2006;4:512-518. DOI: 10.1370/afm.580.

\section{INTRODUCTION}

T nterval breast cancers are those that are not detected on routine screening mammography or that develop within the time interval between screening mammograms. Most research on interval breast cancers has focused on the characteristics of pathology that would identify the cancers' speed of growth or aggressiveness ${ }_{1}^{1-3}$ the quality of the mammographic image ${ }^{4}$ the interpretive ability of the radiologists, ${ }^{5-7}$ or a combination of these issues. ${ }^{8}$ Retrospective review studies on interpretive performance indicate that $15 \%$ to $30 \%$ of interval cancers appeared on the original screening mammogram initially interpreted as negative ${ }_{1}^{5-8}$ which means that the remaining $70 \%$ to $85 \%$ are generally more aggressive tumors. The sensitivity of screening mammography in the United States is $72.4 \%$ to $80.1 \%{ }^{9,10}$; thus, approximately $20 \%$ to $28 \%$ of breast cancers are interval cancers.

Little attention has been paid to how interval breast cancers are ultimately discovered. Women undergoing routine clinical breast examinations and screening mammography who receive a report of normal findings may be unlikely to conduct routine breast self-examination. 
Given the US Preventive Services Task Force does not recommend breast self-examination because of lack of evidence on its effectiveness, ${ }^{11}$ primary care clinicians might not recommend this screening activity to their patients. We conducted an observational study of 143 women with interval breast cancers to determine how their cancers were discovered, and we assessed factors associated with discovery. We hypothesized that interval cancers would be discovered equally (1) by women with a breast cancer concern initiating a health care visit, (2) by the women's primary care clinician finding a breast problem during a routine health maintenance visit, or (3) by the next screening (for the purposes of our study, we defined this as the examination following within 365 days of the initial screening mammogram interpreted as normal). We further hypothesized that interval cancer discovery would be influenced by the patient's age, education, relationship with her health care professional, and tumor size, which may additionally be affected by the time interval between the initial screening mammogram and the date of diagnosis.

\section{METHODS}

\section{Patient Identification and Data From the New Hampshire Mammography Network}

We used the New Hampshire Mammography Network $(\mathrm{NHMN}){ }_{1}^{12}$ a statewide mammography registry, to identify women undergoing screening mammography between January 1, 2000, and December 31, 2002. Details of the NHMN are described elsewhere. ${ }^{12}$ Briefly, the NHMN records breast imaging events for consenting women in New Hampshire; participation is voluntary, with $28(84.9 \%)$ of 33 mammography facilities enrolled in the registry. The composition of participating sites includes hospitals (58\%), clinic-based or outpatient facilities and breast imaging centers (24\%), and physicians' private offices (18\%). Approximately $90 \%$ of all women undergoing mammography at participating centers consent to provide data to the NHMN.

Data collection procedures associated with the NHMN have been approved by the Committee for the Protection of Human Subjects at Dartmouth College. These data include demographic, risk factor, and health history information (obtained through a selfadministered questionnaire), history of previous breast procedures (eg, breast reduction, implants, biopsy, surgery, radiation therapy); personal history of breast cancer and family history of breast cancer (ie, occurrence in a first-degree relative); menopausal status and current use of hormone replacement therapy (HRT) (obtained in a face-to-face interview by the radiology technician); and breast density, mammographic interpretation, and follow-up recommendations assessed by the radiologist using the Breast Imaging Reporting and Data System (BI-RADS) categories of the American College of Radiology (ACR). ${ }^{13}$ Benign and malignant pathology data are collected from participating pathology laboratories, and breast cancer cases are routinely supplemented by the New Hampshire State Cancer Registry for capture of cancers in New Hampshire that bypassed pathology laboratories. The ascertainment, linking, and coding of pathology data are also described in more detail elsewhere. ${ }^{12}$

\section{Procedures for Interval Cancer Discovery Study}

We identified 624 women with a diagnosis of breast cancer within the study period (2000-2002). A total of $481(77 \%)$ of the women had a screen-detected cancer, which was defined as a cancer diagnosed within 90 days of a bilateral screening mammogram interpreted as abnormal using BI-RADS categories 0 (needs additional assessment), 4 (suspicious abnormality), and 5 (highly suggestive of malignancy). ${ }^{13} \mathrm{~A}$ total of 143 (23\%) of the women had an interval cancer, which was defined as a cancer diagnosed within 365 days of a bilateral screening mammogram that was interpreted as normal using BI-RADS category 1 (negative), category 2 (benign finding with routine follow-up recommended), and category 3 (short-interval follow-up). ${ }^{13}$

We obtained the women's demographic and risk information from the NHMN database and identified the primary care clinician who recommended the original screening mammogram associated with detection of the interval cancers. We developed and pilot-tested a data collection instrument to be completed only by the health care clinicians of the women with interval cancers. The instrument determined the patients' status in the practice, how their breast cancer was discovered, the actions taken and dates of events after the breast cancer was found, patient breast concerns known to the clinicians, and patient outcomes as of December 31, 2003.

To pilot-test the data collection form, we asked several primary care clinicians (2 family physicians, 1 internist, and 1 nurse-practitioner) to review the form and attempt to complete it for designated patients. We conducted cognitive interviews to revise the instrument until it could be accurately and consistently completed. The data collection form was then mailed to the primary care clinicians of women with interval cancers. A second mailing was undertaken within 3 weeks of the first if no response was received. Of the 143 forms mailed to primary care clinicians, 101 forms (70.6\%) were completed, 22 (15.4\%) were partially completed, and 20 (14.0\%) were not returned, even after 2 mailed attempts.

For some aspects of our study, it was important to 
compare the characteristics of the women and tumors according to the mechanism of cancer detection (screen-detected vs interval cancers). We created an analytic file with the characteristics of all women receiving a diagnosis of breast cancer during the study period and compared characteristics between women with screendetected cancers and women with interval cancers. Descriptive statistics were calculated for both continuous and categorical data. Continuous data were compared using the $t$ test, and categorical data were compared using the Fisher exact test. ${ }^{14}$ All tests were 2 -tailed with $\alpha$ set at .05 . For main analyses, only the 101 women with complete data were included. The strengths and weaknesses of this approach are debated in the Discussion below.

\section{RESULTS}

The mean age of women with interval cancers was 59.7 years (range $=35-89$ years, $\mathrm{SD}=$ 12.7 years), and the mean age of women with screen-detected breast cancers was 60.1 years (range $=34-96$ years, SD $=12.6$ years) (Table 1). Among women with interval cancers, 78 (54.6\%) were current patients of the practice of the referring primary care clinician; 9 (6.3\%) were no longer patients of the practice, $6(4.2 \%)$ had been referred to another physician, $6(4.2 \%)$ were still patients of the practice but were no longer patients of the clinician referring them for the mammogram, 23 (16.1\%) were considered to be in an "other" category, and 21 (15\%) had missing data for this measure (data not shown). Women with interval cancers were twice as likely to have a personal history of breast cancer $(30.1 \%)$ as women with screen-detected cancers $(13.6 \%)$. The time since the
Table 1. Characteristics of Women With Screen-Detected and Interval Cancers

\begin{tabular}{|c|c|c|c|}
\hline Characteristic & $\begin{array}{c}\text { Women With } \\
\text { Screen-Detected } \\
\text { Cancers } \\
(n=481) \\
\text { No. }(\%)\end{array}$ & $\begin{array}{l}\text { Women With } \\
\text { Interval Cancers } \\
(\mathrm{n}=143) \\
\text { No. }(\%)\end{array}$ & $P$ Value \\
\hline Age at diagnosis, years & & & .67 \\
\hline$\leq 39$ & $8(1.7)$ & $4(2.8)$ & \\
\hline $40-49$ & $106(22.0)$ & $35(24.5)$ & \\
\hline $50-59$ & $140(29.1)$ & $36(25.2)$ & \\
\hline $60-69$ & $100(20.8)$ & $34(23.8)$ & \\
\hline$\geq 70$ & $127(26.4)$ & $34(23.8)$ & \\
\hline Education* & & & .50 \\
\hline Less than high school & $30(6.8)$ & $7(5.2)$ & \\
\hline High school graduate or GED & $125(28.3)$ & $34(25.2)$ & \\
\hline Some college or technical school & $128(29.0)$ & $48(35.6)$ & \\
\hline College or postcollege graduate & $159(36.0)$ & $46(34.1)$ & \\
\hline Insurance* & & & .04 \\
\hline Yes & $449(95.5)$ & $140(99.3)$ & \\
\hline No & $21(4.5)$ & $1(0.7)$ & \\
\hline Family history of breast cancer* & & & .82 \\
\hline Yes & $193(40.4)$ & $60(42.0)$ & \\
\hline No & $279(58.4)$ & $82(57.3)$ & \\
\hline Don't know & $6(1.3)$ & $1(0.7)$ & \\
\hline Personal history of breast cancer* & & & $<.001$ \\
\hline Yes & $65(13.6)$ & $43(30.1)$ & \\
\hline No & $413(86.4)$ & $100(69.9)$ & \\
\hline $\begin{array}{l}\text { Menopausal status and current } \\
\text { HRT use* }\end{array}$ & & & .58 \\
\hline Premenopausal & $119(27.1)$ & $35(27.1)$ & \\
\hline Postmenopausal, no HRT & $210(47.7)$ & $56(43.4)$ & \\
\hline Postmenopausal, HRT & $111(25.2)$ & $38(29.5)$ & \\
\hline Breast density* & & & .48 \\
\hline Fatty & $25(5.5)$ & $5(3.5)$ & \\
\hline Scattered density & $213(46.6)$ & $66(46.2)$ & \\
\hline Heterogeneously dense & $184(40.3)$ & $56(39.2)$ & \\
\hline Extremely dense & $35(7.7)$ & $16(11.2)$ & \\
\hline $\begin{array}{l}\text { Time since the mammogram } \\
\text { before the one associated with } \\
\text { the cancer diagnosis* }\end{array}$ & & & .001 \\
\hline Never had one & $22(5.5)$ & $2(1.5)$ & \\
\hline$<1$ year & $81(20.1)$ & $35(25.9)$ & \\
\hline $1-2$ years & $228(56.4)$ & $89(65.9)$ & \\
\hline$>2$ years & $73(18.1)$ & $9(6.7)$ & \\
\hline $\begin{array}{l}\text { Time since the CBE before the } \\
\text { one associated with the cancer } \\
\text { diagnosis* }\end{array}$ & $4(1.5)$ & $2(3.1)$ & .77 \\
\hline Never had one & $200(76.1)$ & 48 (73.9) & \\
\hline$<1$ year & $47(17.9)$ & $13(20.0)$ & \\
\hline $1-2$ years & $12(4.6)$ & $2(3.1)$ & \\
\hline$>2$ years & & & \\
\hline \multicolumn{4}{|c|}{ GED = graduate equivalent degree; $\mathrm{HRT}=$ hormone replacement therapy; $\mathrm{CBE}=$ clinical breast examination. } \\
\hline \multicolumn{4}{|c|}{$\begin{array}{l}\text { * Missing: } 47 \text { for education ( } 39 \text { screen, } 8 \text { interval); } 13 \text { for insurance ( } 11 \text { screen, } 2 \text { interval); } 3 \text { for family his- } \\
\text { tory of breast cancer (all screen); } 3 \text { for personal history of breast cancer (all screen); } 55 \text { for menopausal status } \\
\text { and HRT use ( } 41 \text { screen, } 14 \text { interval); } 24 \text { for breast density (all screen); } 85 \text { for time since last mammogram } \\
\text { (77 screen, } 8 \text { interval), and } 296 \text { for time since last (BE ( } 218 \text { screen, } 78 \text { interval). }\end{array}$} \\
\hline
\end{tabular}


mammogram before the one associated with the cancer diagnosis was longer among the women with interval cancers than among the women with screen-detected cancers. In addition, the proportion with health insurance was slightly higher in the interval cancer group.

Of the 114 interval cancers detected for which pathology results were available, $100(87.7 \%)$ were invasive and $14(12.3 \%)$ were ductal carcinoma in situ. Among all women with invasive cancers, those with interval cancers had higher-stage disease (stage III or IV: $14.6 \%$ vs $2.7 \%, P<.001)$, had larger tumors ( $\geq 21 \mathrm{~mm}: 38.1 \%$ vs $24.8 \%, P=.02$ ), and more often had positive lymph nodes $(39.5 \%$ vs $26.4 \%, P=.03$ ) than those with screen-detected cancers. A complete comparison of screen-detected and interval cancers is provided in the Appendix. Among women with screen-detected cancers, the mean time from the initial screening mammogram to a breast cancer diagnosis was 18 days $(\mathrm{SD}=14$ days, range $=1-46$ days $)$ for invasive cancers and 20 days $(\mathrm{SD}=13$ days, range $=1$ 48 days) for in situ cancers. Among women with interval cancers, the mean time from the initial screening mammogram to a breast cancer diagnosis was 199 days (SD = 115 days) for invasive cancers and 164 days (SD $=118$ days) for in situ breast cancers (data not shown).

One half $(49.5 \%, 50 / 101)$ of the interval tumors were discovered when women initiated a health care visit because of a breast concern, and $16.8 \%$ were discovered when a primary care clinician found an area of concern while conducting a routine clinical breast examination that was unrelated to symptoms. An additional $22.8 \%$ were discovered when women had their next routine screening mammogram, which was performed before the end of the 365-day follow-up period. No differences were found in discovery scenario by patient age, race, or insurance status (data not shown).

The 101 women with interval cancers included in our main analyses had a total of 229 breast concerns (Table 2). The most common concerns were a personal and/or family history of breast cancer and a lump in the breast. Less frequent concerns included skin changes. The 22 concerns in the "other" category included pain or tenderness $(n=6)$, a problem that had developed in an area of a breast where a previous mammogram had detected a benign abnormality ( $\mathrm{n}$ $=5)$, other concerns $(n=7)$, and no concerns $(n=4)$ (data not shown). The type of concern did not differ by patient age except for concerns about a breast lump: younger women tended to be more likely than their older counterparts to have lumps.

Because most women had more than 1 concern, we organized the presenting concerns into clusters, the most common of which (pertaining to 74 women) are shown in Table 3. Forty-four percent of women initiating a health care visit had a lump and both a personal and a family history of breast cancer. Twenty-four percent of women who initiated a health care visit had a lump, breast pain, and a personal history of breast cancer, while $9 \%$ had only a personal and a family history, and $9 \%$ had only a lump. Of the 23 women with less common discovery scenarios not included in the table, 2 reported skin changes only; 2 reported pain and tenderness only 1 reported skin changes and a personal and family history of breast cancer ${ }_{i} 4$ reported skin changes and a personal history of breast cancer, 2 reported a personal history of breast cancer only; 3 reported a lump, skin changes, and a personal history of breast cancer; and 9 reported other symptoms (not identified).

A total of $59(80 \%)$ of the 74 women with interval cancers and the most common presenting concerns (74 shown in Table 3 and 2 with missing discovery scenarios) were currently patients in the practice, and the health care clinician who referred them for the mammogram that detected their cancer was their primary care clinician. Approximately $8 \%$ had been referred to another physician in the practice, and another $8 \%$ were no longer patients of the practice (data not shown).

Table 2. Distribution of Types of Breast Concerns by Patient Age Among 101 Women With Interval Cancers ( $n=229$ concerns)

\begin{tabular}{|c|c|c|c|c|c|c|}
\hline \multirow[b]{2}{*}{ Breast Concern ${ }^{\dagger}$} & \multicolumn{5}{|c|}{ Age, Years* } & \multirow[b]{2}{*}{$P$ Value } \\
\hline & $\begin{array}{c}\leq 39 \\
\text { No. (\%) }\end{array}$ & $\begin{array}{c}40-49 \\
\text { No. (\%) }\end{array}$ & $\begin{array}{l}50-59 \\
\text { No. (\%) }\end{array}$ & $\begin{array}{l}60-69 \\
\text { No. (\%) }\end{array}$ & $\begin{array}{c}\geq 70 \\
\text { No. (\%) }\end{array}$ & \\
\hline Lump in breast $(n=59)$ & $2(3)$ & $21(36)$ & $15(25)$ & $14(24)$ & $7(12)$ & .2 \\
\hline Skin changes $(n=13)$ & $0(0)$ & $3(23)$ & $2(15)$ & $4(31)$ & $4(31)$ & .72 \\
\hline Family history of breast cancer $(n=61)$ & $2(3)$ & $14(23)$ & $14(23)$ & $17(28)$ & $14(23)$ & .45 \\
\hline Personal history of breast cancer $(n=74)$ & $1(1)$ & $21(28)$ & $18(24)$ & $19(26)$ & $15(19)$ & .37 \\
\hline Other concern $(n=22)$ & $1(5)$ & $4(18)$ & $6(27)$ & $4(18)$ & $7(32)$ & .37 \\
\hline
\end{tabular}




\begin{tabular}{|c|c|c|c|c|c|c|}
\hline \multirow[b]{2}{*}{ Discovery Scenario } & \multicolumn{5}{|c|}{ Cluster of Breast Concerns } & \multirow[b]{2}{*}{$P$ Value* } \\
\hline & $\begin{array}{l}\text { Lump } \\
\text { Only } \\
\text { No. (\%) }\end{array}$ & $\begin{array}{c}\text { Lump, Pain, } \\
\text { Personal History } \\
\text { of Breast Cancer } \\
\text { No. (\%) }\end{array}$ & $\begin{array}{c}\text { Lump, Pain, } \\
\text { Family History } \\
\text { of Breast Cancer } \\
\text { No. (\%) }\end{array}$ & $\begin{array}{c}\text { Lump, Personal } \\
\text { \& Family History } \\
\text { of Breast Cancer } \\
\text { No. }(\%)\end{array}$ & $\begin{array}{l}\text { Personal \& Family } \\
\text { History of Breast } \\
\text { Cancer Only } \\
\text { No. (\%) }\end{array}$ & \\
\hline $\begin{array}{l}\text { Patient initiated health care } \\
\text { visit because of a breast } \\
\text { concern }(n=45)\end{array}$ & $4(9)$ & $11(24)$ & $6(13)$ & $20(44)$ & $4(9)$ & $<.01$ \\
\hline $\begin{array}{l}\text { Clinician found area of } \\
\text { concern while conducting } \\
\text { routine CBE }(\mathrm{n}=11)\end{array}$ & $0(0)$ & $4(36)$ & $3(27)$ & $3(27)$ & $1(9)$ & .15 \\
\hline $\begin{array}{l}\text { Breast cancer was found on } \\
\text { next screening mammo- } \\
\text { gram }(n=14)\end{array}$ & $2(15)$ & $1(7)$ & $1(8)$ & $1(8)$ & $9(64)$ & .001 \\
\hline Other $(n=4)$ & $1(25)$ & $0(0)$ & $1(25)$ & $1(25)$ & $1(25)$ & .43 \\
\hline
\end{tabular}

\section{DISCUSSION}

Of the breast cancers reported to the NHMN during a 24-month period, 1 in 4 was an interval cancer, which is consistent with the sensitivity of mammography previously reported in New Hampshire (74\%). ${ }^{9}$ We originally hypothesized that interval cancers would be equally detected by the women themselves, by their primary care clinicians, and by the next screening mammogram. Approximately one half of women with interval cancers initiated a health care visit when they had 1 or more breast concerns, especially when a lump was accompanied by a personal and family history of breast cancer. Approximately 17\% of the interval cancers were found by women's primary care clinicians, and the remaining interval cancers were picked up on subsequent screening mammograms. As mammography technology improves, it is still critical that primary care clinicians and their patients do not derive false reassurance from a recent negative mammogram. The educational message to report persistent breast symptoms, especially if women are at risk because of a personal or strong family history of breast cancer, cannot be overemphasized. Although many studies have focused on unnecessary biopsies, ${ }^{15,16}$ the majority of these have included mainly women at average risk rather than those at high risk for breast cancer.

Women with invasive interval cancers had larger tumors, had higher stages and grades of breast cancer, and were more likely to have positive lymph nodes than their counterparts with invasive screen-detected cancers. Invasive interval cancers were found about 200 days after the initial screening mammogram, which was approximately 1 month later than in situ interval disease was discovered. This is surprising because in situ disease is often not palpable. We were also surprised to find no differences by age in breast cancer discovery scenario, total number of symptoms or concerns, or cluster of concerns. We had hypothesized that older women would be less likely to detect a lump themselves and initiate a health care visit. Younger women's breasts are often more nodular, which would make detecting a lump more difficult.

Women with interval cancers were much more likely to have a personal history of breast cancer when compared with women with screen-detected cancers. Although conducting breast self-examination has not been found to reduce breast cancer mortality and is not recommended by the US Preventive Services Task Force ${ }^{11}$ as a routine screening procedure for the general public, perhaps it should be recommended for women at high risk for breast cancer, such as those with a personal or family history of the disease. Additional research is needed in this area $a_{\text {however, a }}$ randomized trial may be difficult to conduct because of ethical concerns. Although it is recommended that women with a family history of breast cancer start mammography screening at a younger age, there is no specific recommendation for a screening interval different from that for women in general. ${ }^{11}$ A recent study on the efficacy of breast cancer screening among women at high risk (defined as having a positive family history and a previous breast biopsy) vs average risk (defined as having a negative family history and no previous breast biopsy) found a modest, though not significant association between screening and reduced mortality among women at high risk (odds ratio $=0.74,95 \%$ confidence interval, 0.50 1.03). ${ }^{17}$ This finding further suggests the importance 
of educating high-risk women about the need to see their clinicians if they find an abnormality.

Previous screening history (before the screening mammogram linked to the interval or screen-detected cancer) also differed between women with screendetected vs interval cancers. Women with screendetected cancers were more likely to have their cancer found by the first mammogram they had ever had. No differences were noted by age, education, breast density, family history of breast cancer, menopausal status and use of HRT, or time since last clinical breast examination. We found surprising the lack of difference by breast density and by menopausal status and HRT use, as many studies have found these factors to be associated with difficulty in detecting breast cancer. ${ }^{18-21}$ Although insurance status differed significantly between women with screen-detected cancer and women with interval cancers, it is unclear whether the difference between the proportions with insurance (96\% vs 99\%, respectively) is clinically relevant.

When we assessed patient status in the practice among the women with interval cancers who had the most common breast concerns, we found that most of these women were currently cared for by the health care clinician who had referred them for the mammogram that detected their interval cancer. An important relationship with a primary care physician was thus the primary model of health care for the majority of women in the study. Although we do not know how long the relationship had been established, it is likely an important one for detection of interval cancers. Our data indicate that the interval cancers found were generally more aggressive than the screen-detected cancers, which underscores the importance of surveillance for high-risk women. Previous research has shown that between $70 \%$ and $85 \%$ of interval cancers are not mammographically detectable ${ }^{5-8}$ but are growing rapidly. Initiating a health care visit when an abnormality is found may help to identify these rapidly growing cancers when long-term survival is still possible.

Our study was conducted among a populationbased sample of women undergoing mammography screening, which has both strengths and limitations. A strength is that we were able to identify women with interval cancers for study and, with the help of their primary care clinicians, we were able to obtain information on how their interval cancers were found, a topic that has received little attention in the breast cancer surveillance literature. Our study, however, is only generalizable to women in northern New England who obtained mammograms. Additional research is needed to confirm our findings. A limitation is that many of our analyses were based only on the 101 women for whom we had complete information.
Although these women represented more than $70 \%$ of those with interval cancers, their number was too small to pursue all of our planned analyses. Larger confirmatory studies are needed.

In conclusion, we found that women with interval cancers are most likely to initiate a visit to a health care clinician when they have 2 or more breast-related concerns. These concerns are most likely to include having a lump and a personal and family history of breast cancer. Women at highest risk for breast cancer may need closer surveillance than the general population of women. It may be reasonable to encourage them to seek care from their primary care clinicians if they develop breast symptoms, rather than taking reassurance from a negative screening mammogram.

To read or post commentaries in response to this article, see it online at http://www.annfammed.org/cgi/content/full/4/6/512.

Key words: Mammography screening; breast neoplasms; community health; public health; signs; symptoms; surveillance; health care seeking behavior

Submitted July 21, 2005; submitted, revised, February 14, 2006; accepted March 4, 2006.

Funding support: This work was supported by U01CA86082 of the National Cancer Institute.

\section{References}

1. Cowan WK, Angus B, Gray JC, Lunt LG, al-Tamimi SR. A study of interval breast cancer within the NHS Breast Screening Programme. J Clin Pathol. 2000;53:140-146.

2. DeGroote R, Rush BF Jr, Milazzo J, Warden MJ, Rocko JM. Interval breast cancer: a more aggressive subset of breast neoplasias. Surgery. 1983;94:543-547.

3. Gilliland FD, Joste N, Stauber PM, et al. Biologic characteristics of interval and screen-detected breast cancers. J Natl Cancer Inst. 2000;92:743-749.

4. Taplin SH, Rutter CM, Finder C, et al. Screening mammography: clinical image quality and the risk of interval breast cancer. AJR Am J Roentgenol. 2002;178:797-803.

5. de Rijke JM, Schouten LJ, Schreutelkamp JL, Jochem I, Verbeek AL. A blind review and an informed review of interval breast cancer cases in the Limburg screening programme, the Netherlands. J Med Screen. 2000;7:19-23.

6. Britton PD, McCann J, O'Driscoll D, Hunnam G, Warren RM. Interval cancer peer review in East Anglia: implications for monitoring doctors as well as the NHS Breast Screening Programme. Clin Radiol. 2001;56:44-49.

7. Morrone D, Giorgi D, Ciatto S, et al. Radiologic analysis of interval cancers in the screening program called Florence Woman Project [in Italian]. Radiol Med (Torino). 2000;100:321-325.

8. Vitak B, Olsen KE, Manson JC, Arnesson LG, Stal O. Tumour characteristics and survival in patients with invasive interval breast cancer classified according to mammographic findings at the latest screening: a comparison of true interval and missed interval cancers. Eur Radiol. 1999;9:460-469.

9. Poplack SP, Tosteson AN, Grove MR, Wells WA, Carney PA. Mammography in 53,803 women from the New Hampshire Mammography Network. Radiology. 2000;217:832-840. 
10. Kerlikowske K, Carney PA, Geller B, et al. Performance of screening mammography among women with and without a first-degree relative with breast cancer. Ann Intern Med. 2000;133:855-863.

11. US Department of Health and Human Services. Agency for Healthcare Research and Quality. US Preventive Services Task Force. Screening for breast cancer. 2002. Available at: http://www.ahrq. gov/clinic/uspstf/uspsbrca.htm. Accessed 29 September 2006.

12. Carney PA, Poplack SP, Wells WA, Littenberg B. The New Hampshire Mammography Network: the development and design of a population-based registry. AJR Am J Roentgenol. 1996;167:367-372.

13. The American College of Radiology Breast Imaging and Reporting Data System (BI-RADS). 3rd ed. Reston, Va: American College of Radiology; 1998.

14. Conover WJ. Fisher's exact, most nonparametric. In: Practical Nonparametric Statistics. 2nd ed. New York, NY: John Wiley and Sons; 1980.

15. McCann J, Stockton D, Godward S. Impact of false-positive mammography on subsequent screening attendance and risk of cancer. Breast Cancer Res. 2002;4:R11.

16. Schwartz LM, Woloshin S, Sox HC, Fischhoff B, Welch HG. US women's attitudes to false-positive mammography results and detection of ductal carcinoma in situ: cross-sectional survey. West J Med. 2000;173:307-312
17. Elmore JG, Reisch LM, Barton MB, et al. Efficacy of breast cancer screening in the community according to risk level. J Natl Cancer Inst. 2005;97:1035-1043.

18. Carney PA, Miglioretti DL, Yankaskas BC, et al. Individual and combined effects of age, breast density, and hormone replacement therapy use on the accuracy of screening mammography. Ann Intern Med. 2003;138:168-175.

19. Leung W, Goldberg F, Zee B, Sterns E. Mammographic density in women on postmenopausal hormone replacement therapy. Surgery. 1997;122:669-673; discussion 673-674

20. Persson I, Thurfjell E, Holmberg L. Effect of estrogen and estrogenprogestin replacement regimens on mammographic breast parenchymal density. J Clin Oncol. 1997;15:3201-3207.

21. Rutter CM, Mandelson MT, Laya MB, Seger DJ, Taplin S. Changes in breast density associated with initiation, discontinuation, and continuing use of hormone replacement therapy. JAMA. 2001:285:171-176.

Appendix. Characteristics of Tumors in Women With Screen-Detected and Interval Cancers ( $\mathbf{N}=559)$

\begin{tabular}{|c|c|c|c|c|c|c|}
\hline \multirow[b]{2}{*}{$\begin{array}{l}\text { Tumor } \\
\text { Characteristic* }\end{array}$} & \multicolumn{3}{|c|}{ Invasive Cancers } & \multicolumn{3}{|c|}{ In Situ Cancers } \\
\hline & $\begin{array}{l}\text { Screen-Detected } \\
(n=345) \\
\text { No. }(\%)\end{array}$ & $\begin{array}{c}\text { Interval } \\
(\mathrm{n}=100) \\
\text { No. }(\%)\end{array}$ & $P$ Value & $\begin{array}{c}\text { Screen-Detected } \\
(n=100) \\
\text { No. }(\%)\end{array}$ & $\begin{array}{c}\text { Interval } \\
(n=14) \\
\text { No. }(\%)\end{array}$ & $P$ Value \\
\hline \multicolumn{7}{|l|}{ Stage } \\
\hline I or II & $288(97)$ & $70(85)$ & $<.001$ & NA & NA & NA \\
\hline III or IV & $8(3)$ & $12(15)$ & & & & \\
\hline \multicolumn{7}{|l|}{ Lymph node status } \\
\hline Positive & $71(26)$ & $30(40)$ & .03 & NA & NA & NA \\
\hline Negative & $198(74)$ & $46(61)$ & & & & \\
\hline \multicolumn{7}{|l|}{ Tumor size } \\
\hline$\leq 10 \mathrm{~mm}$ & $92(29)$ & $15(18)$ & .02 & $40(62)$ & $2(25)$ & .08 \\
\hline $11-20 \mathrm{~mm}$ & $144(46)$ & $37(44)$ & & $17(26)$ & $3(38)$ & \\
\hline$\geq 21 \mathrm{~mm}$ & $78(25)$ & $32(38)$ & & $8(12)$ & $3(38)$ & \\
\hline \multicolumn{7}{|l|}{ Tumor grade } \\
\hline 1 or 2 & $159(65)$ & $31(53)$ & .09 & $32(56)$ & $2(40)$ & .49 \\
\hline 3 or 4 & $87(35)$ & $28(48)$ & & $25(44)$ & $3(60)$ & \\
\hline
\end{tabular}

Note: Tumor characteristics were not available for 65 (10\%) of the women (36 screen, 29 interval).

$\mathrm{NA}=$ not applicable

* Missing: 67 for stage (49 screen, 18 interval); 100 for lymph node status (76 screen, 24 interval); 88 for tumor size (66 screen, 22 interval); and 192 for tumor grade (142 screen, 50 interval) 